\title{
WAYANG BEBER PACITAN DALAM ANALISIS STRUKTURAL
}

\author{
Diah Enggarwati \\ Email: diah.enggar@yahoo.com
}

\begin{abstract}
Wayang Beber Pacitan as a myth can be seen as a text, which contains signifier and signified. The characters in the puppet is an intermediary for people to interpret the content in Java and basic human traits. Structural analysis Wayang Beber Pacitan bring the following conclusions: First, that the structure of the three are often found in the Java community. Second, that the ideal marriage expected in Pacitan beber wayang stories are cousins once between the two kingdoms (Kediri and Jenggala), although in the Java community does not explicitly recognize their ideal mate. Third, the story Wayang Beber Pacitan is a political story that serves to legitimize the power of the kingdom of Kediri and Janggala. Fourth, that behind the story is that there is a notion of Java: "sopo kang nandur bakal ngundhuh".
\end{abstract}

Keywords: Wayang Beber Pacitan, structural analysis

\section{PENDAHULUAN}

Wayang bagi orang Jawa merupakan mitologi keagamaan yang diterima secara hampir universal (Laksono, 1985: 22). Dari wayang tampak sekali usaha orang Jawa untuk menjelaskan semesta alam dan posisi kehadirannya sendiri di dalam semesta, yaitu hubungan orang Jawa dengan tata alami dan supra-alami, dengan sesama manusia dan dirinya sendiri. Tokoh-tokoh dalam wayang merupakan perantara bagi orang Jawa untuk menginterpretasikan isi dalam dan ciri dasar manusia. Sebagai sarana komunikasi, wayang memiliki "bahasa" dan kaidah-kaidah tersendiri yang dapat dipahami karena memiliki ketertataan dan keterulangan. Kaidah ini disebut deep structure, yaitu struktur yang tidak nampak, tidak disadari oleh penggunanya, namun bisa diidentifikasi dan diabstraksikan dalam beberapa fenomena budaya sehari-hari (Ahimsa-Putra, 2006: 61). Setiap fenomena budaya dipandang sebagai sebuah mitos, yang memiliki struktur luar (surface structure) dan struktur dalam (deep structure). Struktur luar adalah struktur yang dibangun atas relasi antarunsur dalam tataran fakta-fakta empiris, sedangkan struktur dalam adalah struktur yang dibangun atas relasi antarrelasi yang diperoleh dari analisis struktur luar. Dari deep structure inilah dapat diperoleh makna tersembunyi di balik apa yang tampak (hidden meaning).

Wayang Beber Pacitan sebagai mitos di sini dapat dipandang sebagai sebuah teks. Namun demikian, perlu diingat bahwa menurut Lévi-Strauss, mitos berada pada level yang lebih atas dan kompleks daripada level kebahasaannya. Oleh karena itu, dalam analisisnya tidak hanya berada pada tataran fenomena kebahasaan saja (Lévi-Strauss, 1967: 206 - 207). Artinya, dalam memahami sebuah ceritera wayang tidak cukup menafsirkan apa yang diceriterakan (struktur luar) saja, tetapi mencari apa yang tidak diceriterakan atau yang ada di balik yang diceriterakan (struktur dalam). 
Wayang Beber Pacitan merupakan dunia simbol yang di dalamnya mengandung penanda (signifier) dan tinanda (signified). Sebagai sarana komunikasi, Wayang Beber Pacitan memiliki aspek langue dan parole yang berada dalam bingkai jagad pewayangan. Di dalamnya juga terdapat sisi sinkronis dan diakronis yang keduanya diberlakukan bersama-sama. Makna Wayang Beber Pacitan dibangun atas relasi antarunsur pokok (miteme), baik hubungan secara sintagmatik maupun paradigmatik. Hubungan sintagmatik sebuah adegan adalah hubungan yang dimilikinya dengan adegan sebelum atau sesudahnya. Dengan demikian, hubungan sintagmatik adalah jalinan miteme-miteme dalam membentuk rangkaian kisah yang bermakna (AhimsaPutra, 2006: 47). Sebuah adegan apabila kehilangan beberapa hubungan sintagmatiknya atau memperoleh hubungan sintagmatik yang baru (berbeda), ia akan berubah maknanya atau bahkan menjadi tidak bermakna (Ahimsa-Putra, 2006: 49). Sedangkan hubungan paradigmatik adalah hubungan-hubungan esensial yang dimilikinya, yang memisahkan berbagai perbedaan dalam rangka pendefinisian simbol tersebut (Ahimsa-Putra, 2006: 49). Artinya, bahwa hubungan paradigmatik dalam wayang adalah suatu asosiasi yang secara referensial telah dimiliki masyarakat pendukungnya atas sebuah simbol.

Tulisan ini mencoba menerapkan analisis struktural Lévi-Strauss untuk mengungkapkan makna atau memberi makna baru dari ceritera Wayang Beber Pacitan meski tidak pada tataran yang sempurna. Seperti Ahimsa-Putra yang menghadirkan makna baru dalam tulisannya mengenai dongeng Bajo (Pitoto' Si Muhamma'), tulisan ini juga berusaha menunjukkan bahwa ceritera Wayang
Beber Pacitan sebenarnya merupakan wujud dari sebuah upaya kognitif dalam menyelesaikan suatu konflik dalam masyarakat Jawa.

\section{JAKA KEMBANG KUNING DAN DEWI SEKARTAJI: SEBUAH KISAH, SEBUAH CERITERA}

Ringkasan ceritera Wayang Beber Pacitan di bawah ini diperoleh berdasarkan penuturan Dalang Wayang Beber Pacitan (Rudhi Prasetyo) yang kemudian dituangkan dalam bentuk tulisan. Selain berdasarkan penuturan Rudhi, ceritera Wayang Beber Pacitan ini disempurnakan dengan mengadopsi dari tulisan lain mengenai kisah Jaka Kembang Kuning (Enggarwati, 2013).

Gulungan 1 Adegan Pertama. Prabu Brawijaya (raja dari Kerajaan Kediri) memanggil para pembantunya, termasuk Patih Prawira Arya Deksa Negara. Patih Arya Deksa yang saat itu sedang membahas keamanan negara dengan para bawahannya segera menghadap sang raja dengan tergesa-gesa. Prabu Brawijaya mengatakan kepada Patih Arya Deksa bahwa tujuannya memanggil sang patih adalah untuk memberitahu bahwa putrinya, Dewi Sekartaji, telah melarikan diri dari istana. Dewi Sekartaji melarikan diri karena menolak untuk menikah dengan Raden Klana Sewandana dari Kerajaan Seberang. Rupa-rupanya, Dewi Sekartaji telah memiliki tambatan hati sendiri. Prabu Brawijaya akan mengadakan sayembara bagi siapa saja yang dapat menemukan Dewi Sekartaji, tanpa memandang derajat atau pangkat, kaya atau miskin, bangsawan atau rakyat jelata, apabila dia perempuan akan dijadikannya saudara dari Dewi Sekartaji dan apabila laki-laki akan dijadikannya suami dari Dewi Sekartaji. Patih Arya Deksa kemudian 
mengumumkan

sayembara tersebut

kepada seluruh penduduk.

\section{Gulungan 1 Adegan Kedua.}

Beberapa waktu kemudian, ada seorang pemuda yang menghadap raja untuk mengikuti sayembara tersebut. Raja heran melihat kesaktian pemuda itu, karena banteng yang ada di alun-alun tunduk seakan memberi hormat kepadanya. Raja bertanya-tanya: "Siapakah gerangan pemuda ini?". Raja menanyakan hal itu kepada Patih Arya Deksa. Nama pemuda itu adalah Jaka Kembang Kuning, utusan dari Ki Demang Kuning. Raja memerintahkan untuk memanggil Jaka Kembang Kuning. Raja menanyakan kesanggupan Jaka Kembang Kuning untuk mencari Dewi Sekartaji. Jaka Kembang Kuning tidak diperbolehkan kembali ke Kerajaan Kediri sebelum menemukan Dewi Sekartaji. Jaka Kembang Kuning menyanggupi permintaan raja untuk mencari Dewi Sekartaji yang tidak lain adalah kekasihnya sendiri.

Gulungan 1 Adegan Ketiga. Jaka Kembang Kuning mohon diri untuk segera mencari keberadaan Dewi Sekartaji bersama dua orang abdinya, yaitu $\mathrm{Ki}$ Tawang Alun dan Ki Naladerma. Dalam perjalanan mencari Dewi Sekartaji, Jaka Kembang Kuning bertemu dengan tiga orang ksatria, yaitu: Ganggawercitra, Jaladara, dan Gendrayuda. Ketiga ksatria ini mengajukan keing inannya pada Jaka Kembang Kuning agar dirinya dijadikan sebagai abdi. Jaka Kembang Kuning mengetahui bahwa sebenarnya ketiga kesatria itu adalah pengikut Raden Klana Sewandana yang disuruh untuk mematamatai Jaka Kembang Kuning yang dapat mengancam keselamatan jiwanya. Jaka Kembang Kuning menolak keinginan ketiga ksatria itu dan menyarankan agar mengabdikan diri pada Raden Gandarepa salah satu putra Prabu Brawijaya di Kerajaan Kediri. Saran Jaka Kembang Kuning diterima dan masing-masing melanjutkan perjalanannya. Di tengah perjalanan, Ki Tawang Alun menyarankan Jaka Kembang Kuning cara untuk mencari Dewi Sekartaji, yaitu dengan mengadakan pertunjukan Barong Terbang (semacam kesenian terbangan) di Pasar Katumenggungan. Pertunjukan Barong Terbang adalah pertunjukan yang sangat digemari Dewi Sekartaji.

Dewi Sekartaji yang melarikan diri dari istana ternyata menuju ke kediaman $\mathrm{Ki}$ Tumenggung di Katumenggungan Paluamba. Pada saat itu, Nyi dan Ki Tumenggung sedang berdebat masalah mimpi Nyi Tumenggung yang kejatuhan wahyu kembar. Tiba-tiba mereka dikejutkan oleh kedatangan Dewi Sekartaji. Nyi dan Ki Tumenggung takut jika nanti dituduh menyembunyikan Dewi Sekartaji. Akhirnya Dewi Sekartaji dimarahi Nyi dan Ki Tumenggung. "Kamu itu jangan keluarkeluar dari Keputren. Kalau dilamar Raden Klana itu kamu harusnya tidak menolak.", kata Nyi Tumenggung. "Tidak, mbok. Saya tidak mau. Saya hanya mencintai Jaka Kembang Kuning. Kalau memang tidak mengijinkan saya di sini, saya akan pergi.", kata Dewi Sekartaji. Akhirnya Dewi Sekartaji pergi.

Gulungan 1 Adegan Keempat. Saran Ki Tawang Alun untuk mengadakan pertunjukan Barong Terbang segera dilakukan oleh Jaka Kembang Kuning. Jaka Kembang Kuning menyamar sebagai pengamen dan mengadakan pertunjukan Barong Terbang di pasar. Dewi Sekartaji yang pada saat itu berada di pasar dan melihat pertunjukan Barong Terbang, akhirnya bertemu dengan Jaka Kembang Kuning. "Dewi Sekartaji, kamu di sini?", tanya Jaka Kembang Kuning. "Kakang, 
kamu di sini?". Dewi Sekartaji terkejut melihat Jaka Kembang Kuning menyamar sebagai pengamen. Jaka Kembang Kuning berpesan kepada Dewi Sekartaji untuk merahasiakan pertemuan antara Jaka Kembang Kuning dengan Dewi Sekartaji. Jaka Kembang Kuning kembali ke kediamannya, Kademangan Kuning. Sedangkan Dewi Sekartaji kembali ke Katumenggungan Paluamba.

Gulungan 2 Adegan Pertama. Setelah sampai di kediamannya, Jaka Kembang Kuning menghadap sang ayah, Ki Demang Kuning. "Bagaimana? Kamu disuruh apa di Kediri?", tanya Ki Demang Kuning. "Saya disuruh mencari Dewi Sekartaji.", jawab Jaka Kembang Kuning. "Sudah ketemu?", tanya Ki Demang Kuning. "Sudah.”, jawab Jaka Kembang Kuning. Jaka Kembang Kuning menceritakan kepada sang ayah bagaimana dia bisa menemukan Dewi Sekartaji. Jaka Kembang Kuning kemudian mengutus Ki Tawang Alun untuk menghadap Prabu Brawijaya dan memberitahukan bahwa Jaka Kembang Kuning telah menemukan putrinya, Dewi Sekartaji. Sedangkan Ki Naladerma diutus untuk memberikan cincin tunangan kepada Dewi Sekartaji ke kediaman Ki Tumenggung Paluamba sebagai bukti bahwa Jaka Kembang Kuning sudah menemukan Dewi Sekartaji.

Gulungan 2 Adegan Kedua. Retno Mindoko beserta beberapa orang abdi sedang menenun kain di Keputren. Tibatiba datanglah rombongan perempuan utusan dari Raden Klana Sewandana untuk melamar Dewi Sekartaji. Rombongan itu dipimpin oleh Retno Tenggaron. Retno Tenggaron bersama para abdinya membawa seserahan dari Raden Klana Sewandana untuk melamar Dewi Sekartaji. Retno Mindoko menolak lamaran tersebut karena Dewi Sekartaji menghilang dari Keputren.
Gulungan 2 Adegan Ketiga. Retno Tenggaron tidak terima karena lamaran Raden Klana Sewandana ditolak oleh Retno Mindoko. Akhirnya, terjadi pertempuran antara Retno Mindoko dan para abdinya melawan Retno Tenggaron dan para abdinya. Dalam pertempuran ini, Retno Tenggaron kalah dan akhirnya mundur ke Raden Klana Sewandana.

Gulungan 2 Adegan Keempat. Di teratebang (depan kerajaan), Raden Gandarepa dan Patih Sedahrama sedang berbincang-bincang. Lalu, datanglah $\mathrm{Ki}$ Tawang Alun. Raden Gandarepa mengantarkan Ki Tawang Alun ke hadapan Prabu Brawijaya. Ki Tawang Alun menceritakan apa yang terjadi kepada Raden Gandarepa dan Prabu Brawijaya. Ki Tawang Alun menjelaskan bahwa Jaka Kembang Kuning berhak memperistri Dewi Sekartaji. Tiba-tiba datanglah Raden Klana Sewandana yang mengatakan akan memboyong Dewi Sekartaji untuk menjadi istrinya, sehingga terjadilah adu mulut antara Ki Tawang Alun dan Raden Klana Sewandana.

Gulungan 3 Adegan Pertama. Ki Naladerma menghadap Jaka Kembang Kuning. "Bagaimana lamaranku?", tanya Jaka Kembang Kuning. "Dewi Sekartaji menerimanya, Raden." Ki Naladerma menjawab. Jaka Kembang Kuning riang gembira setelah mengetahui bahwa lamarannya diterima oleh Dewi Sekartaji.

Gulungan 3 Adegan Kedua. Pertemuan antara Raden Klana Sewandana dan Patih Kebo Lorodan, di markas tentara Raden Klana Sewandana. Raden Klana Sewandana dan Patih Kebo Lorodan membicarakan perihal tantangan untuk mengalahkan Ki Tawang Alun sebagai salah satu syarat untuk dapat memperistri Dewi Sekartaji. Tidak lama kemudian, datang Retno Tenggaron melaporkan 
bahwa dirinya telah dipermalukan oleh Retno Mindoko karena lamaran Raden Klana Sewandana ditolak. Raden Klana Sewandana marah dan akan menuntut balas atas perlakuan pada adiknya. Untuk memenuhi tantangan Prabu Brawijaya, Patih Kebo Lorodan diminta untuk maju ke medan perang melawan Ki Tawang Alun. Patih Kebo Lorodan menyanggupinya.

Gulungan 3 Adegan Ketiga. Di Kademangan Kuning, Jaka Kembang Kuning mohon diri pada $\mathrm{Ki}$ Demang Kuning untuk menyusul Ki Tawang Alun yang telah beberapa waktu belum kembali dari Kerajaan Kediri. Jaka Kembang Kuning memberitahukan kepada $\mathrm{Ki}$ Demang Kuning bahwa di Kerajaan Kediri sedang terjadi perang tanding untuk memperebutkan Dewi Sekartaji. Ki Demang Kuning mengijinkan permintaan Jaka Kembang Kuning. Jaka Kembang Kuning dan Ki Naladerma menyusul Ki Tawang Alun ke Kerajaan Kediri.

Gulungan 3 Adegan Keempat. Di alun-alun Kerajaan Kediri, Patih Kebo Lorodan bertarung melawan Ki Tawang Alun dengan disaksikan oleh para punggawa dan prajurit Kerajaan Kediri, serta pengikut Raden Klana Sewandana. Pada pertarungan itu, Ki Tawang Alun kalah. Ki Tawang Alun terluka parah.

Gulungan 4 Adegan Pertama. Ki Naladerma membawa Ki Tawang Alun ke kediaman Ki Tumenggung dan Ki Tawang Alun disembuhkan oleh Dewi Sekartaji.

Gulungan 4 Adegan Kedua. Jaka Kembang Kuning yang melihat Ki Tawang Alun dikalahkan oleh Patih Kebo Lorodan akhirnya mengambil alih posisi Ki Tawang Alun. Patih Kebo Lorodan bertarung dengan Jaka Kembang Kuning. Pada pertarungan ini, Patih Kebo Lorodan mati. Raden Klana Sewandana mundur, mengatur kekuatan untuk menyerang Kerajaan Kediri.

Gulungan 4 Adegan Ketiga. Raden Gandarepa beserta abdinya datang ke Kademangan Kuning untuk bertemu dengan Jaka Kembang Kuning dan menyampaikan pesan dari Prabu Brawijaya, bahwa Prabu Brawijaya dan Raden Gandarepa memiliki rencana untuk mengalahkan Raden Klana Sewandana yang licik. Raden Gandarepa menceritakan rencananya kepada Jaka Kembang Kuning. Jaka Kembang Kuning menyetujui rencana tersebut.

Gulungan 4 Adegan Keempat. Raden Gandarepa menemui Ki Tawang Alun dan menyampaikan pesan Prabu Brawijaya, yaitu mengutus $\mathrm{Ki}$ Tawang Alun: "Hai, Tawang Alun. Kalau kamu sudah sembuh, akan kuberi pusaka dari kerajaan. Bunuh Raden Klana!' Ki Tawang Alun diminta untuk membunuh Raden Klana Sewandana dan yang membunuh Raden Klana Sewandana haruslah Ki Tawang Alun.

Gulungan 5 Adegan Pertama. Di kediamannya, Raden Klana Sewandana meminta adiknya, Retno Tenggaron, untuk merubahnya menjadi Raden Gandarepa palsu. Tidak ada yang tahu mana yang Raden Klana Sewandana dan mana yang Raden Gandarepa. Hanya Ki Tawang Alun lah yang tahu, sehingga yang harus membunuh Raden Klana Sewandana adalah Ki Tawang Alun.

Gulungan 5 Adegan Kedua. Raden Klana Sewandana berubah menjadi Raden Gandarepa palsu untuk melamar Dewi Sekartaji. Di Tamansari Kerajaan Kediri, Dewi Sekartaji yang baru saja kembali dari Katumenggungan Paluamba menerima kedatangan Raden Gandarepa (tiruan). Karena gerak geriknya yang mencurigakan, Dewi Sekartaji menolaknya. "Kamu bukan Raden Gandarepa. Kamu Raden Klana 
Sewandana.", kata Dewi Sekartaji. Raden Gandarepa (asli) datang, "Kamu menyamar sebagai saya!". Akhirnya terjadi peperangan. Raden Klana Sewandana segera lari ke alun-alun Kerajaan Kediri.

Gulungan 5 Adegan Ketiga. Di alunalun Kerajaan Kediri, Raden Klana Sewandana yang dikejar Raden Gandarepa menemui para pengikutnya. Sementara Jaka Kembang Kuning dan Ki Tawang Alun telah siap melakukan pertarungan melawan Raden Klana Sewandana dan pengikutnya. Akhirnya, terjadilah perang besar-besaran.

Gulungan 5 Adegan Keempat. Raden Klana Sewandana akhirnya dibunuh oleh Ki Tawang Alun dengan menggunakan Keris Pasopati. Setelah Raden Klana Sewandana mati, kemenangan ada di tangan Jaka Kembang Kuning dan Ki Tawang Alun.

Gulungan 6 Adegan Pertama. Jaka Kembang Kuning memboyong para tawanan putri, termasuk Retno Tenggaron, ke hadapan Prabu Brawijaya di Keraton Kerajaan Kediri. Prabu Brawijaya menerima para tawanan dan laporan tentang berbagai kejadian sejak hilangnya Dewi Sekartaji sampai terbunuhnya Raden Klana Sewandana.

Gulungan 6 Adegan Kedua. Jaka Kembang Kuning dan Dewi Sekartaji meminta doa restu kepada Prabu Brawijaya, disaksikan oleh adiknya, Raden Gandarepa, Ki Naladerma dan Ki Tawang Alun.

Gulungan 6 Adegan Ketiga. Pelaksanaan pernikahan Jaka Kembang Kuning dan Dewi Sekartaji yang akan dirias oleh Mbok Dipa Kilisada.

Gulungan 6 Adegan Keempat. Persetubuhan Jaka Kembang Kuning dan Dewi Sekartaji setelah pelaksanaan pernikahan.

\section{ANALISIS STRUKTURAL WAYANG BEBER PACITAN}

Analisis di sini dilakukan seperti langkah analisis Ahimsa-Putra dalam dongeng Bajo Pitoto' Si Muhamma'. Langkah pertama adalah membaca keseluruhan ceritera terlebih dahulu. Dari pembacaan ini diperoleh pengetahuan dan kesan tentang isi ceritera, tentang tokohtokohnya, tentang berbagai tindakan yang mereka lakukan, serta berbagai peristiwa yang mereka alami. Untuk mempersingkat ceritera dan memudahkan analisisnya, ceritera Wayang Beber Pacitan perlu dibagi menjadi beberapa episode. Sedikit berbeda dengan pembagian episode Ahimsa-Putra dalam Pitoto' Si Muhamma', ceritera Wayang Beber Pacitan di sini hanya dibagi menjadi 3 (tiga) episode.

Setiap episode ini umumnya berisi deskripsi tentang tindakan atau peristiwa yang dialami oleh tokoh-tokoh dalam ceritera (Ahimsa-Putra, 2006: 204). Tindakan atau peristiwa ini merupakan miteme, yang hanya dapat ditemukan pada tingkat kalimat. Untuk menemukan miteme-miteme dapat dilakukan dengan memperhatikan rangkaian kalimat-kalimat yang memperlihatkan adanya suatu ide tertentu. Dengan cara ini, akan diperoleh rangkaian-rangkaian kalimat yang memperlihatkan suatu 'pengertian' tertentu, yang kemudian disebut Ahimsa-Putra sebagai ceriteme. Ceriteme adalah sebuah unit yang mengandung pengertian tertentu yang - seperti halnya miteme - hanya dapat diketahui maknanya atau 'pengertiannya' setelah ditempatkan dalam hubungan dengan ceriteme-ceriteme yang lain (Ahimsa-Putra, 2006: 206). Ceriteme ini bisa mendeskripsikan suatu pengalaman, sifat-sifat, latar belakang kehidupan, interaksi atau hubungan sosial, status sosial ataupun hal-hal lain dari lakon-lakon 
ceritera yang penting artinya bagi analisis.

Berikut adalah pembagian episode beserta tafsirnya.

\section{Episode 1: Masalah}

Dewi Sekartaji (DS) dari Kerajaan Kediri kabur dari rumah karena menolak lamaran Raden Klana Sewandana (KS) dari Kerajaan Seberang. Ayah DS, Prabu Brawijaya (B) mengadakan sayembara untuk mencari DS. Sayembara diperuntukkan bagi siapa saja yang dapat menemukan DS, tanpa memandang derajat atau pangkat, kaya atau miskin, bangsawan atau rakyat jelata, apabila dia perempuan akan dijadikannya saudara dari DS dan apabila laki-laki akan dijadikannya suami dari DS (Gulungan 1 Adegan Pertama). Jaka Kembang Kuning (JKK) dari Kerajaan Jenggala muncul di Kerajaan Kediri untuk mengikuti sayembara pencarian DS (Gulungan 1 Adegan Kedua). JKK menyanggupi permintaan B untuk tidak kembali ke Kerajaan Kediri sebelum menemukan DS. Dengan menyamar sebagai pengamen pertunjukan Barong Terbang, JKK akhirnya berhasil menemukan DS, yang tidak lain adalah kekasihnya sendiri (Gulungan 1 Adegan Keempat). Sedangkan KS yang tidak mengikuti sayembara, dia tiba-tiba datang di Kerajaan Kediri dan mengatakan akan memboyong DS untuk menjadi istrinya (Gulungan 2 Adegan Keempat). Ceritera mengenai DS, JKK, dan KS tersebut dapat digambarkan sebagai berikut.

Tafsir Episode 1. Di sini dapat ditafsirkan bahwa KS adalah putra raja dari Kerajaan Seberang karena gelar "Raden" diasumsikan digunakan untuk para putra mahkota dan jika dia seorang raja, maka dia akan bergelar "Prabu". Selain itu, untuk menduduki tahta kerajaan sebagai raja, maka dia seharusnya sudah memiliki permaisuri. Keinginan KS untuk melamar dan memperistri KS secara tersirat menunjukkan bahwa KS belum memiliki istri, sehingga memperkuat dugaan bahwa posisi KS adalah sebagai putra mahkota.

Di sini terlihat adanya oposisi antara KS dengan JKK. JKK datang ke Kerajaan Kediri dengan penuh rasa hormat dan santun, sedangkan KS datang dan malah membuat kegaduhan dengan adu mulut bersama Ki Tawang Alun (TA), utusan JKK. JKK mengikuti sayembara yang diadakan B untuk mencari DS sebagai jalan memperistri DS, sedangkan KS tidak mengikuti sayembara namun ingin segera memboyong DS ke Kerajaan Seberang. Terlihat di sini bagaimana KS tidak dianggap sebagai ksatria karena tidak melakukan sayembara layaknya ksatria sejati zaman kerajawian. Berbeda dengan JKK yang secara jantan mengikuti sayembara dan menyanggupi permintaan $\mathrm{B}$ untuk menemukan DS dengan cara terhormat.

Sayembara pencarian DS yang diumumkan oleh $\mathrm{B}$ adalah masalah yang mendasari terjadinya konflik antara JKK dengan KS. Namun keputusan B di sini menunjukkan sikap bijak seorang raja yang dipandang telah berlaku adil karena sayembara tidak hanya diperuntukkan bagi kaum-kaum ningrat, namun juga berlaku bagi rakyat jelata. Dalam hubungan ini orang Jawa berdasar atas konsep jumbuhing kawula-Gusti, menganggap bahwa raja dan rakyat sama pentingnya berbeda lebih karena fungsinya (keduniawian) daripada karena nilainya (transenden-esensial) (Laksono, 1985). Orang Jawa secara tersirat mengidam-idamkan suatu keadaan yang tatatentrem, karena jumbuhing kawulaGusti adalah satu-satunya jalan menuju tatatentrem. Adapun konsekuensi lain dari konsep jumbuhing kawula-Gusti sebagai 
raja idaman, terdapat simpul pada pikiran orang Jawa bahwa raja memiliki kekuatan maha besar untuk mengembalikan keadaan jika ada kekisruhan (kekacauan). Di sini B memiliki peran sebagai raja idaman, karena mampu menemukan solusi dalam mencari anaknya yang lari dari Keputren.

\section{Episode 2: Cara Penyelesaian Masalah}

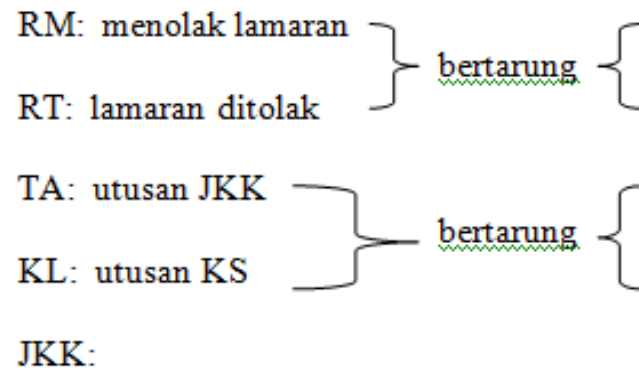

Ada beberapa scene dalam episode kedua ini, karena posisinya yang berada di puncak-puncak konflik.

(1) JKK mencari DS bersama dengan dua abdinya, TA dan Ki Naladerma (ND). TA menyarankan JKK untuk menyamar menjadi pengamen pertunjukan Barong Terbang di Pasar Katumenggungan. DS yang menyukai pertunjukan Barong Terbang datang dan bertemu JKK (Gulungan 1 Adegan Keempat). Sedangkan KS dengan bantuan adiknya, Retno Tenggaron (RT), merubah dirinya menjadi Raden Gandarepa (G) palsu sebagai upaya untuk bertemu dan melamar DS. Namun DS menyadari gerak-gerik G (palsu) yang mencurigakan, sehingga penyamaran KS terbongkar (Gulungan 5 Adegan Kedua).

\section{Tafsir Episode 2}

(1) Terlihat jelas di sini terdapat oposisioposisi antara JKK dengan KS. Untuk mendapatkan DS, mereka sama-sama menyamar. Namun rupa-rupanya trik JKK lebih mampu membuat DS jatuh hati daripada trik yang dilakukan KS.

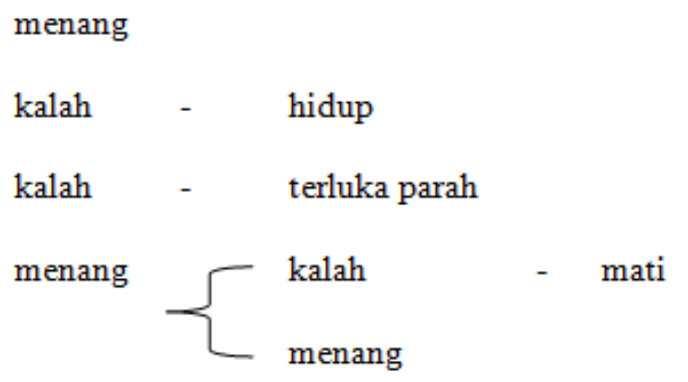

JKK menyamar sebagai pengamen Barong Terbang, sedangkan KS menyamar sebagai kakak DS. Dapat dikatakan pula di sini terdapat oposisi "panggedhe" dan "wong cilik". KS yang menyamar menjadi $G$ adalah representasi "panggedhe", sedangkan JKK yang menyamar menjadi pengamen adalah representasi dari "wong cilik".

(2) Retno Mindoko (RM) kedatangan rombongan perempuan utusan dari KS untuk melamar DS yang dipimpin oleh RT. RM menolak lamaran tersebut karena DS menghilang dari Keputren (Gulungan 2 Adegan Kedua). RT yang tidak terima lamarannya ditolak akhirnya bertarung dengan RM. RT kalah dan mundur memberitahu KS (Gulungan 2 Adegan Ketiga). Mendengar laporan RT, KS marah besar dan menyuruh Patih Kebo Lorodan (KL) untuk bertarung melawan TA sebagai syarat memperistri DS. Di alun-alun Kerajaan Kediri, KL bertarung melawan TA. Pada pertarungan itu, TA kalah dan terluka parah (Gulungan 3 Adegan Keempat). JKK 
yang melihat TA dikalahkan oleh KL akhirnya mengambil alih posisi TA. Pada pertarungan ini, KL mati dan KS mundur mengatur kekuatan untuk menyerang Kerajaan Kediri (Gulungan 4 Adegan Kedua).

(3) Tafsir Episode 2 (2). Di sini terlihat oposisi-oposisi antarlakon yang melakukan pertempuran. Pertarungan antara RM dengan RT yang dilatarbelakangi penolakan lamaran KS oleh RM dimenangkan RM, RT kalah namun masih bisa menyelamatkan diri. Sedangkan pertarungan antara TA dengan KL dimenangkan oleh KL dan menyebabkan TA luka parah. Oposisi ini kemudian dinetralkan oleh JKK yang memenangkan pertarungan dengan KL. Dalam pertarungan keduanya, KL mati. Di sini terdapat dua oposisi pada satu lakon, yaitu KL: (menang - hidup) dan (kalah mati).

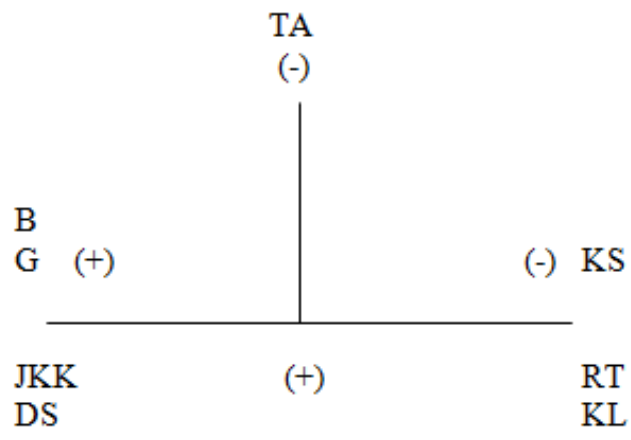

(4) G beserta abdinya datang ke Kademangan Kuning untuk bertemu dengan JKK dan menyampaikan pesan dari $B$, bahwa $B$ dan $G$ memiliki rencana untuk mengalahkan KS yang licik. JKK menyetujui rencana tersebut (Gulungan 4 Adegan Ketiga). G kemudian menemui TA dan menyampaikan pesan B, yaitu mengutus TA untuk membunuh KS dengan pusaka pemberian B (Gulungan 4 Adegan Keempat).

Tafsir Episode 2 (3). Di sini ditekankan bahwa "yang membunuh KS haruslah TA". Hal ini menimbulkan pertanyaan, mengapa harus TA yang membunuh KS? Mengapa bukan JKK? Pertanyaan ini dapat dijawab salah satunya dengan mengadopsi model "segitiga tegak" (upright triangle) Ahimsa-Putra (2006). Dalam konteks ini, lakon TA berada pada kutub anti-struktur, sedangkan lakon B, G, DS, JKK, KS, RT, dan Patih Kebo Lorodan (KL) berada dalam dunia struktur, yang dapat digambarkan seperti berikut. Struktur di atas menggambarkan konsepsi nalar masyarakat Jawa dalam menampilkan keteraturan, tatanan (order), serta pandangan bahwa segala sesuatu harus temata (tertata). Konsepsi ketertataan ini dalam nalar masyarakat Jawa memiliki tiga komponen, yakni: kesatuan (unity), kesinambungan (continuity), dan keselarasan (harmony) (Helman, 1988). Dalam segitiga tegak di atas, TA menjadi elemen tengah/elemen "antara" yang menjembatani oposisi binair yang telah ada. Dengan adanya elemen "antara" ini, maka terbentuklah kesinambungan dan kesatuan yang juga menciptakan adanya keselarasan antara komponen yang satu dengan yang lain. Sedangkan dalam konteks politik/kekuasaan, "keharusan" TA untuk membunuh KS tidak dipandang sebagai sebuah perintah, namun lebih sebagai sebuah tanggung jawab. TA sebagai abdi dari JKK memiliki kewajiban untuk melindungi dan menjadi tameng JKK dalam posisi 
bahaya. Jika dalam pertempuran TA tidak berhasil membunuh KS bahkan mati di tangan KS, maka artinya TA berhasil melalui perannya sebagai seorang abdi karena mati demi melindungi junjungannya. Sebaliknya jika TA berhasil membunuh KS, maka adalah suatu kebanggaan tersendiri bagi TA karena mampu melakukan tugasnya dengan amat baik. Kehadiran TA di tengah KS dan JKK ini menguntungkan JKK. Jika TA kalah, JKK masih bisa menyerang KS. Jika TA menang, JKK tidak perlu bersusah-payah melumuri tangannya dengan darah untuk membunuh KS.

\section{Episode 3: Hasil yang Dicapai}

KS akhirnya dibunuh oleh TA dengan menggunakan Keris Pasopati. Setelah KS mati, kemenangan ada di tangan JKK dan TA (Gulungan 5 Adegan Keempat). JKK menghadap B dengan membawa tawanan puri dan melaporkan kejadian sejak hilangnya DS hingga terbunuhnya KS (Gulungan 6 Adegan Pertama). Akhirnya, JKK menikah dengan DS (Gulungan 6 Adegan Ketiga).

$\begin{array}{lll}\text { JKK: } & \text { hidup } & \text { menang } \\ \text { TA: membunuh } & \text { hidup } & \text { menang } \\ \text { KS: dibunuh } & \text { mati } & \text { kalah }\end{array}$

Tafsir Episode 3. Di sini dapat ditafsirkan bahwa B sebagai seorang raja yang adil dan bijak menepati janjinya. Seperti konsep masyarakat Jawa bahwa seorang raja harus mampu menciptakan suasana jumbuhing kawula-Gusti yang menjadi jalan menuju tatatentrem. Selain itu, dalam episode terakhir ini sebenarnya menunjukkan pernikahan ideal antara
Kerajaan Kediri dengan Kerajaan Jenggala. Telah disebutkan di atas bahwa JKK berasal dari Kerajaan Jenggala dan DS berasal dari Kerajaan Kediri. Jika ditelusuri dari sejarah kerajaan, ternyata kedua kerajaan ini dahulunya adalah satu kerajaan milik Raja Airlangga.

Seperti dilansir dari beberapa sumber, bahwa pada tahun 1041 atau 963 M, Raja Airlangga memerintahkan membagi kerajaan menjadi dua bagian. Kerajaan tersebut dibagi untuk menghindari terjadinya pertikaian akibat perebutan tahta dua putra Raja Airlangga. Pembagian kerajaan tersebut dilakukan oleh seorang Brahmana yang terkenal akan kesaktiannya, yaitu Mpu Bharada. Kedua kerajaan tersebut dikenal dengan Jenggala (Kahuripan) dan Panjalu (Kediri) yang dibatasi oleh Gunung Kawi dan Sungai Brantas. Kejadian ini dikisahkan dalam prasasti Mahaksubya (1289 M), kitab Negarakertagama (1365 M), dan kitab Calon Arang (1540 M) Kerajaan Jenggala yang berada di sisi Timur diberikan kepada Mapanji Garasakan. Kerajaan Jenggala meliputi daerah Malang dan delta sungai Brantas dengan pelabuhannya di Surabaya, Rembang, dan Pasuruan. Ibu kota Kerajaan Jenggala berada di kota lama, yaitu Kahuripan. Sedangkan Kerajaan Panjalu, yang kemudian dikenal dengan nama Kediri, berada di sisi Barat diberikan kepada Sri Samarawijaya. Wilayah Kerajaan Panjalu meliputi Kediri dan Madiun. Ibu kota Kerajaan Panjalu berada di kota baru, yaitu Daha.

Berdasar atas sejarah kerajaan tersebut, maka dapat ditafsirkan bahwa sebenarnya JKK dan DS adalah saudara sepupu sekali. B adalah paman JKK. Jadi di sini jelas bahwa pernikahan ideal yang diharapkan adalah saudara sepupu sekali antara kedua kerajaan (Kediri dan 
Jenggala). Hal ini tidak menutup kemungkinan bagi kita untuk menyimpulkan bahwa dalam ceritera Wayang Beber Pacitan juga terdapat larangan incest, yakni menikah dengan orang di luar kedua kerajaan tersebut, sehingga menikah dengan KS pada dasarnya adalah suatu larangan incest. Meskipun dalam masyarakat Jawa tidak ada penekanan jodoh ideal, mereka meyakini jodoh yang harus dihindari. Berkenaan dengan hal ini, orang Jawa mengenal istilah sirikan jejodhohan, yakni orang-orang yang harus dihindari (disiriki), terlarang sebagai jodoh, dan yang paling terlarang adalah jejodhohan, pernikahan, di antara dua saudara sekandung atau antara dua orang anggota dari sebuah keluarga inti (AhimsaPutra, 2006: 408). Pernikahan semacam ini diyakini mendatangkan kutukan/bencana di kemudian hari.

Secara umum, masyarakat Jawa, khususnya yang tinggal di pedesaan, tidak mengenal jodoh ideal. Namun, dalam beberapa kelompok masyarakat Jawa masih terdapat konsep bobot, bibit, bébét dalam hal memilih menantu. Bobot adalah kualitas seseorang, bibit adalah dari keturunan siapa, dan bébét berorientasi pada status sosial. Bébét (status sosial) ditentukan oleh bobot (kualitas) dan bibit (keturunan). Pernikahan yang dianggap ideal dalam masyarakat Jawa, terutama yang berasal dari kalangan priyayi adalah pernikahan dengan orang yang baik bobot, bibit, bébétnya. Tiga "B" inilah yang seringkali dijadikan dasar oleh orang tua atau keluarga untuk menentukan pantas tidaknya atau baik buruknya calon jodoh seseorang. Terlihat di sini bahwa bébét JKK lebih tinggi daripada KS yang ditunjukkan dari kesaktian JKK (bobot) yang lebih unggul dari KS, meskipun secara bibit keduanya berada pada posisi yang seimbang.

Yang lebih penting lagi di sini adalah, bahwa ceritera Wayang Beber Pacitan ini merupakan ceritera politik di mana sebenarnya memiliki fungsi untuk melegitimasi kekuasaan kedua kerajaan (Kediri dan Jenggala) agar tidak jatuh ke tangan raja dari kerajaan lain, mengingat sejarah kedua kerajaan yang berasal dari satu induk kerajaan milik Raja Airlangga, yakni Kerajaan Medang Kamulan. Pernikahan JKK dengan DS merupakan cara terbaik untuk mengikat kedua kerajaan menjadi satu.

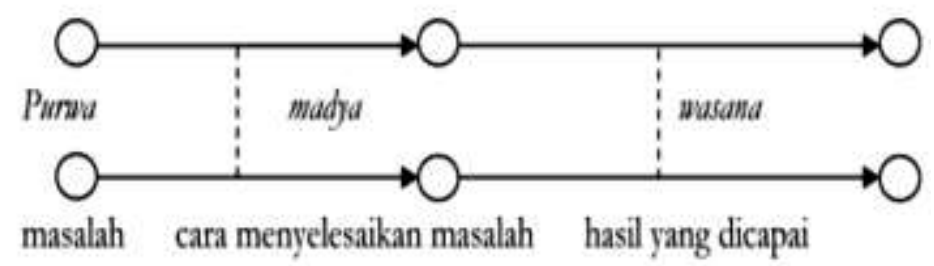

Sumber: Wahyudi, 2008

STRUKTUR DALAM KONTEKS BUDAYA JAWA

Dalam laku Jawa terdapat konsep purwa - madya - wasana yang pada dasarnya terdiri dari tiga unsur, yaitu: permasalahan - cara menyelesaikan masalah - hasil dari penyelesaian masalah. Struktur konsep purwa - madya - wasana adalah sebagai berikut.

Struktur tiga juga dijumpai dalam konsep kekuasaan Jawa. Bagi masyarakat Jawa, raja merupakan simbol kesempurnaan 
di mana keberadaan dan keagungannya diakui oleh rakyatnya berdasarkan peranannya sebagai wakil Tuhan untuk mengayomi dan mengatur tata kehidupan di bumi. Mengingat kapasitas yang demikian, maka seorang raja harus mampu menciptakan suasana jumbuhing kawulaGusti, yaitu hubungan yang harmonis layaknya ikatan keluarga, baik antara penguasa dengan rakyat maupun antara rakyat dengan rakyat. Selain itu, struktur tiga juga dijumpai dalam masyarakat Jawa dalam konsep kekerabatan (memilih menantu), yakni bobot, bibit, bébét. Bobot adalah kualitas seseorang, bibit adalah dari keturunan siapa, dan bébét berorientasi pada status sosial. Relasi tiga unsur tersebut adalah bébét (status sosial) ditentukan oleh bobot (kualitas) dan bibit (keturunan).

Pernikahan yang dianggap ideal dalam masyarakat Jawa, terutama yang berasal dari kalangan priyayi adalah pernikahan dengan orang yang baik bobot, bibit, bébét-nya. Tiga "B" inilah yang seringkali dijadikan dasar oleh orang tua atau keluarga untuk menentukan pantas tidaknya atau baik buruknya calon jodoh seseorang. Dengan adanya kriteria tiga "B" ini, maka orang Jawa tidak menganggap pernikahan dengan kerabat sendiri merupakan pernikahan yang ideal, kecuali jika mereka memenuhi kriteria tiga "B" tersebut karena tidak setiap kerabat memiliki nilai tiga "B" yang sama. Bahkan di beberapa keluarga, pernikahan dengan kerabat sendiri cenderung dihindari karena orang Jawa biasanya lebih memilih "orang lain" untuk dijadikan menantu daripada kerabat sendiri. Beberapa orang justru beranggapan, menikah dengan kerabat sendiri walaupun secara Islam dan adat tidak dilarang, namun dinilai tidak pantas. Biasanya, orang Jawa lebih memperhatikan ucapan/bisik-bisik tetangga daripada harus menikahkan putra-putrinya dengan kerabat sendiri. Menikah dengan kerabat sendiri seringkali menjadi sebuah gunjingan dalam lingkungan bertetangga, dan itu sangat mengganggu kehidupan rumah tangga. Selain itu pula, orang Jawa lebih suka jika hubungan kekerabatan mereka menjadi lebih luas dan menciptakan relasi-relasi baru. Bagi orang Jawa, lebih penting kaya saudara atau kerabat daripada kaya harta.

Satu hal lagi yang perlu digarisbawahi bahwa dalam masyarakat Jawa terdapat ungkapan "sopo kang nandur bakal ngundhuh" (siapa yang menanam akan menuai), dan ceritera Wayang Beber Pacitan ini meyakinkan para penontonnya bahwa barang siapa yang menyebarkan kebaikan, akan memperoleh kebaikan dan sebaliknya, barang siapa yang menyebarkan keburukan, akan memperoleh keburukan pula. Terlihat dari JKK yang digambarkan sebagai lakon baik (protagonis) mendapat akhir yang baik, sedangkan KS yang digambarkan sebagai lakon jahat (antagonis) mendapat akhir yang mengenaskan. Orang Jawa percaya bahwa ketika mereka melakukan kebaikan, maka mereka akan mendapatkan kebaikan pula.

\section{KESIMPULAN}

Analisis struktural Wayang Beber Pacitan di atas membawa kita pada kesimpulan berikut: Pertama, bahwa struktur tiga banyak dijumpai dalam masyarakat Jawa, seperti: konsepsi nalar masyarakat Jawa dalam menampilkan keteraturan, tatanan (order), serta pandangan bahwa segala sesuatu harus temata (tertata). Konsepsi ketertataan ini dalam nalar masyarakat Jawa memiliki tiga komponen, yakni: kesatuan (unity), kesinambungan (continuity), dan keselarasan (harmony). Konsep purwa madya - wasana yang pada dasarnya terdiri 
dari tiga unsur, yaitu: permasalahan - cara menyelesaikan masalah - hasil dari penyelesaian masalah. Konsep kekuasaan Jawa: Dewa - Raja - Rakyat, serta konsep bobot, bibit, dan bébét dalam hal pernikahan ideal. Kedua, bahwa sebenarnya JKK dan DS sebenarnya adalah saudara sepupu sekali. Di sini jelas bahwa pernikahan ideal yang diharapkan adalah saudara sepupu sekali antara kedua kerajaan (Kediri dan Jenggala), walaupun dalam masyarakat Jawa tidak dengan tegas mengenal jodoh ideal. Namun hal ini tidak menutup kemungkinan juga terdapat larangan incest, yakni menikah dengan orang di luar kedua kerajaan tersebut, sehingga menikah dengan KS pada dasarnya adalah suatu larangan incest. KS dinilai tidak pantas memperistri DS karena dari Kerajaan Seberang. Ketiga, ceritera Wayang Beber Pacitan ini merupakan ceritera politik di mana sebenarnya berfungsi untuk melegitimasi kekuasaan kedua kerajaan (Kediri dan Jenggala) agar tidak jatuh ke tangan raja dari kerajaan lain, mengingat sejarah kedua kerajaan yang berasal dari satu induk kerajaan Airlangga (Medang Kamulan). Keempat, tetap saja di balik semua itu terdapat satu gagasan Jawa: sopo kang nandur bakal ngundhuh.

\section{DAFTAR PUSTAKA}

Ahimsa-Putra, Heddy Shri. 2006. Strukturalisme Lévi-Strauss: Mitos dan Karya Sastra. Yogyakarta: Kepel Press.

Anonim. 2014. "Sejarah Kerajaan Kediri", (Online)

http://www.portalsejarah.com/sejara h-kerajaan-kediri.html, diakses tanggal 14 November 2016).
Enggarwati, Diah. 2013. "Aktualisasi Wayang Beber Sebagai Sumber Nilai Karakter Lokal (Studi Kasus Keberadaan Wayang Beber Di Desa Nanggungan Kecamatan Pacitan Kabupaten Pacitan)". Skripsi tidak diterbitkan. Surabaya: Jurusan PMPKn UNESA.

Helman, S. 1988. "The Javanese Conception of Order and Its Relationship to Millenarian Motifs and Imagery". International Journal of Comparative Sociology XXIX (12): 126-138.

Laksono, PM. 1985. Tradisi Dalam Struktur Masyarakat Jawa: Kerajaan dan Pedesaan. Yogyakarta: Gadjah Mada University Press.

Lévi-Strauss, Claude. 1967. Structural Anthropology. New York: Anchor Books, Doubleday and Company, INC.

Rahmawati, Arvina. 2011. "Wayang Beber Di Desa Gedompol Kecamatan Donorojo Kabupaten Pacitan dan Fungsinya Dalam Kehidupan Masyarakat". Skripsi tidak diterbitkan. Surabaya: Jurusan Pendidikan Sejarah FIS UNESA.

Suharyono, Bagyo. 2005. Wayang Beber Wonosari. Wonogiri: Bina Citra Pustaka.

Wahyudi. 2008. "Lakon Wahyu Cakraningrat dalam Paradigma Strukturalisme”. Jurnal Resita 